\title{
Non-destructive Testing of Duralumin and Titanium Alloys
}

\author{
Dmitriev Sergey, Malikov Vladimir, Sagalakov \\ Anatoly, Katasonov Alexander, Ekkerdt Kirill \\ Faculty of physics and technology \\ Altai State University, ASU \\ Barnaul, Russia \\ dmitrsf@gmail.com
}

\author{
Ishkov Alexey \\ Faculty of physics and technology \\ Altai State Agrarian University, ASAU \\ Barnaul, Russia \\ alekseyyishk@rambler.ru
}

\begin{abstract}
The article presents the structure of a subminiaturized eddy-current transducer (EST) of a transformer type with the exciting, measuring and compensation windings, which is based on the pyramid-shaped core providing the localization of the magnetic field on the area of $0.0025 \mathrm{~mm}^{2}$. It also presents the main transducer parameters that allow providing this localization of the magnetic field. A measurement procedure that allows one to perform high-accuracy monitoring of flaws in different alloys is described. The eddy-current transducer was successfully tested on several objects, e.g., a 5.5 $\mu \mathrm{m}$ thick duralumin alloy and welded seams of $5 \mathrm{~mm}$ thick titanium plates. The penetration depth of the field of eddy currents into the investigated object is determined and the dependences, describing the response of the ECT at different depths of the defect, are outlined. The dependences of the ECT signal on the flaws in these structures are given.
\end{abstract}

Keywords-eddy-current transducer; titanium alloys; duralumin; measuring system; filter

\section{INTRODUCTION}

Nondestructive testing is relevant in terms of degradation of the material during the operation with long service life without the possibility of replacement or major repairs of the product. Issues conserning defectoscopy occupy an important place in modern applied phisics and industry.

In traditional industries of developed countries the quality control costs in average are accounted for 1-3\% of production cost. In defence, nuclear and aerospace industries the quality control costs reach up to $12-20 \%$.

Despite the significant number of modern facilities and methods of defectoscopy, only a few of them allow a quick scanning. Most of flaw detection methods may be used only in the laboratory, using complex technical instruments. The portable methods of diagnostic of the materials relatively are not much functional. Despite the possibility of finding defects, the equipment is not designed to evaluate the degradation of material, thus the conclusion of the possible life-time period and its risk breakdowns can not be formed.

This can be explained by innability of equipment of simultaneously scaning at different depths, identifying of ultrasmall defects and real time scanning analysis. In this context, an urgent task is to develop eddy-current measurement systems based on miniature and subminiature eddy-current transducers designed for local measurement of electrical conductivity in inhomogeneous materials, as well as identification of defects in alloys and engineering system security prognosis.

Ownig to a good combination of strength and lightness, $\mathrm{Al}-\mathrm{Mg}$ alloys are used as structural materials in aircraft and astronautics, as well as in the electrical, chemical and food industries.

The defects in alloys can be both identified in stage of molding and stage of production, for instance, because for poor quality welding. The quality control of these alloys and their products is an urgent problem; investigations are making progress in this direction.

L. Barbato et al. [1] scanned two aluminum plates with a model flaw in the center and tested cracks between the plates. The diameter of the measuring winding was $7 \mathrm{~mm}$. The scanning was performed at 1 and $5 \mathrm{kHz}$. In this case, the penetration depth of eddy currents into the studied plates at the above mentioned frequencies was 3.82 and $1.71 \mathrm{~mm}$.

The analisys of recently conducted investigations indicates the tendency of minisizing of eddy-current transducers (EST). Transducers with a size of $5 \times 5 \mathrm{~mm}$ and a $0.15 \mathrm{~mm}$ diameter of the wire have been designed [2]. However, they do not provide the required penetration depth and localization of the magnetic field that are necessary for local measurements in different nonuniform media. Ferrite magnetic field concentrators are often used to increase the area of the magnetic field. A similar design provides an advantage that is related to the absence of the scatter of eddy currents [3]. In addition, a $2.5 \mathrm{~mm}$ penetration depth is attained.

In this connection, the challenge is to design subminiature eddy-current transducers that provide a penetration depth of up to $5 \mathrm{~mm}$ and an area of $2500 \mu \mathrm{m}^{2}$. Since the eddy-current inspection method is insensitive to non conducting paint layers, it can also be used for diagnosing parts with paint coats.

Titanium alloy is widely used in aerospace industry and military products because of its excellent over-all properties. 
Laser welding is greatly fitted to weld titanium alloy sheets because of its marked features such as energy concentration, small heat input, good formation of weld, purification effects and so on. However, porosities and other defects will occur in the weld because of quick cooling velocity and bad protection [4]. Pores and other defects may cause a reduction of solidity of metal of construction, and thus lead to destruction of the material. According to this, a non-destructive control for construction security is of high interest. The designed by $\mathrm{W}$. Deng and other scientists tree-dimensional software environment for non-destructive control is based on automatic designing system which is configured to quick and securely evaluate the structure integrity of aircraft parts with complex structure [5]. .X.E. Gross and other scientists used eddy current and thermography control for identifying of poorquality carbon fiber [6].

Ultrasonic testing (UT) of titanium welds has low repeatability, low sensitivity, high cost and high intrusion into the manufacturing process. Unlike radiography, conventional UT is not designed to detect pore less than $2 \mathrm{~mm}$ in welding joints of titanium alloy [7]. Also Horn in his work indicates on possible detection of subsurface pores with diameter of titanium (UNS R56401) approximately of 0.2-0.3 mm, which thickness is accounted for $30 \mathrm{~mm}$ using high sensitivity radiography [8]. Eddy current testing is being considered as a replacement for the penetrant testing of titanium based components. Past experiments demonstrated that testing of titanium components can be accomplished using significantly high frequencies in the ECT range [9].

\section{MATERIALS AND MEASUREMENT PROCEDURE}

A subminiaturized eddy-current transducer [10, 11] is designed for the local examination of thickness of different coatings in experiments and also for identification of influence of different coatings on the out signal quantity.

The design of the measuring system includes two differentially connected subminiature transducers, which provide a large area of the magnetic field.

The tested parameter is the electric conductivity of the material and its distribution over the studied object. The eddycurrent transducer is connected to a set of the designed amplifiers and band-pass filters and is controlled by the sound map of a personal computer with special software, which applies a voltage to the generator winding of the transducer. This allows one to read the voltage values from the measuring winding initially in some arbitrary units, which are further translated into electric-conductivity values, taking the preliminary calibration into account.

The exciting winding of the transducer consists of ten turns; its diameter is $0.12-0.13 \mathrm{~mm}$. The measuring winding consists of 130 turns and has a diameter of $0.05-0.08 \mathrm{~mm}$. A copper wire with a $5 \mathrm{~mm}$ diametr is used for producing turns. To minimize the influence if existing winding in the recording signal, the circuit contains a compensation winding that is connected to measuring winding in accordance with well- known differential circuit. This consists of 20 turns. A copper wire with a 5-pm thickness is used for winding turns. The turns are wound around a pyramidal core. The proposed shape of the core is favorable for the area of the magnetic field. The core is made of ferrite with an initial magnetic permeability of $500 \mathrm{H} / \mathrm{m}$.

Different transducers that are based on cores that have the same ratio of the base diagonal $(400 \mathrm{pm})$ and edge length (1 $\mathrm{mm}$ ) were calibrated using samples with a well-known electric conductivity.

The characteristics of the constructed transducers allow one to efficiently localize the magnetic field within $2500 \mu \mathrm{m}^{2}$ and larger and to ensure a large (up to $5 \mathrm{~mm}$ ) depth of penetration into the investigated object in operation at relatively low frequencies.

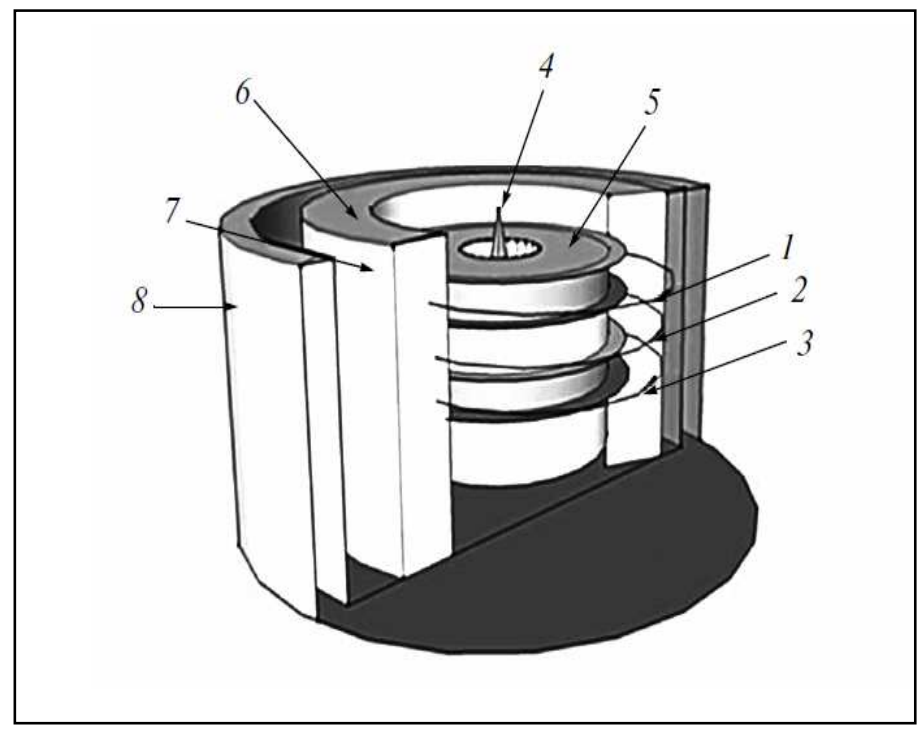

Fig. 1. A block diagram of the eddy-current transducer

The eddy-current transducer (Fig. 1) is a transformer with measuring (1), exciting (2), and compensation (3) windings and magnetic circuit 4, which is located inside cylindrical platform 5 with tracks that are cut on the external side for windings. The platform is impregnated with compound 6 at a temperature of $200^{\circ} \mathrm{C}$ to prevent the disintegration of the windings when ferrite screen 7 , which is intended for the localization of the electromagnetic field on the tested object, is put in place. From the outside, the transducer is contained in corundum washer 8 , which protects core 4 from contacting the tested object.

The core consists of a tetrahedral pyramid (height $1 \mathrm{~mm}$ ), with a square base (sides of $0.2 \mathrm{~mm}$ ). The measuring winding rests on the points of the pyramid, which improves the localization of the magnetic field. Such transducers permit effective localization of the magnetic field, so that defects as small as $250 \mu \mathrm{m}$ may be detected. In addition, the magnetic field penetrates into the sample to a considerable depth when working at relatively low frequencies. 


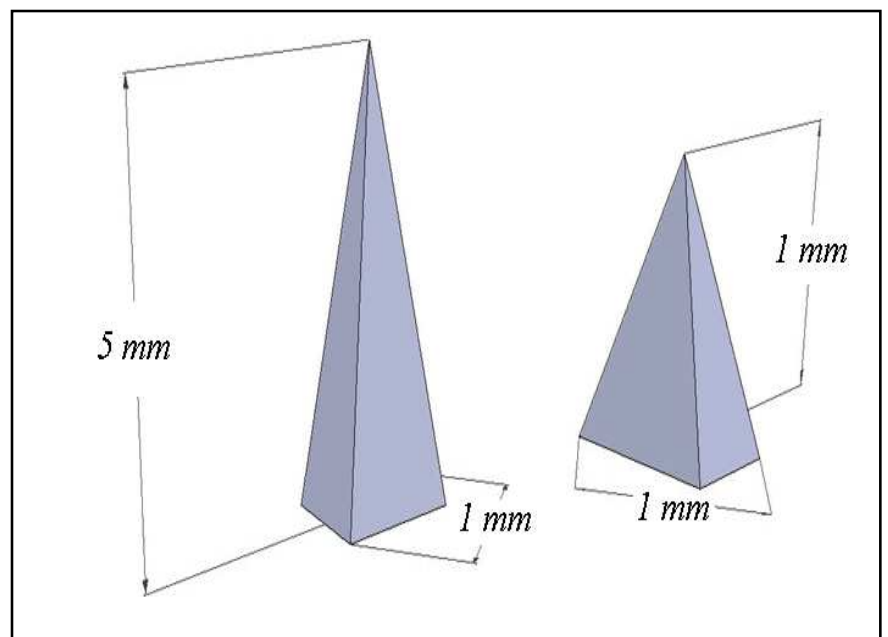

Fig. 2. The cores of different sizes

The core has shape of pyramid. This kind of shape was achieved mainly in two ways. First of all there was a cut of thin $(0.1 \mathrm{~mm})$ triangles from 81NMA alloy. After that the triangles were put together and their upper parts were ground off. This kind of approach has its disadvantages: the tops are ground off unevenly, as the result, the magnetic field was rather weak.

The second way to make pyramid shaped core was grinding off the thin triangles, and further composing them into a pyramid.

Wire coils were placed on the pyramid shaped cores. The coils were impregnated with the compound. The temperature of impregnation was 200 degrees Celsius, the diameter of the wire was $1,5 \times 10^{-6}$ meters. The measuring winding was placed at the end of the top of the pyramid, the diameter of the winding was $0.05 \mathrm{~mm}$., the number of winds varied from 100 up to 200. In the middle of the pyramid, there was an actuating winding that consisted of one wind. The compensating winding was situated on the mobile frame and included 100 wires. The mobile frame enables it to move freely along the oxide core from the bottom up to the actuating winding.

The authors have made 10 ECTs. To subtract the directed current from the actuating winding into the measuring one, the authors have retrofitted all the devices. The authors made different ECTs because they wanted to obtain the magnetic field of different tension. That is why the cores differed from each other in size. The correlation between the diagonal of the bottom and the edge of the pyramid varied from 1:1 to $1: 10$ (Fig.2).
The ETCs constructed on the basis of the cores, having a similar correlation between the diagonal of the base (400 $\mathrm{mkm})$ and the length of the rib $(4 \mathrm{~mm})$, have been calibrated on semi-conductors with the certain conductivity (Picture 4). Thus, the ECTs have identical geometric parameters of the cores and the same number of the winds of the actuating (1

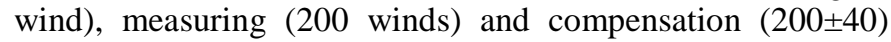
windings.

The measuring system, which is based on a miniature eddy-current transducer, operates as follows. The software of the personal computer controls the operation of the generator, which produces a train of rectangular voltage pulses with repetition rate $f_{1}$ that is necessary for the operation of the eddy-current transducers. The voltage pulses are transmitted from the generator output to two series integrators. They are then directed to the input of the power amplifier. From the amplifier output, the voltage pulses arrive at the exciting inductance coils of the eddy-current transducers. The difference of the output voltages of the measuring coils of the transducers contains information on the structural heterogeneities of the tested object that is located in the effective area of the eddy-current transducers. It is detected and amplified in a special microphone amplifier. After passing through two high-quality low-frequency filters and selective amplifier, the signal arrives at the amplitude detector. The signal is then transmitted through an analog-to-digital converter to a personal computer. Due to the simultaneous control of the generated signal frequency at the exciting coil and the cutoff frequency of the filtering system and the selective amplification, the useful signal, which contains information on the electric conductivity distribution inside the object, in particular, on possible flaws of the object, is detected. The control program allows one to change the operating frequency of the measuring system so that the signal that is received from the measuring winding is reliably recorded.

\section{EXPERIMENTAL RESULTS}

\section{A. Scanning the duralumin D16AM}

Experiments are conducted on D16T duralumin plates 1 and 2. Plate 1 (thickness $5.5 \mathrm{~mm}$ ) has three defects: notches (width $1 \mathrm{~mm}$ ) that end at distances of 1,3 , and $4 \mathrm{~mm}$, respectively from the opposite surface (Fig. 3.a). Plate 2 (thickness $5.5 \mathrm{~mm}$ ) has six defects: notches (width $0.25 \mathrm{~mm}$ ) that end at distances of $1,2,3,4,5$, and $5.3 \mathrm{~mm}$, respectively from the opposite surface (Fig. 3.b). 


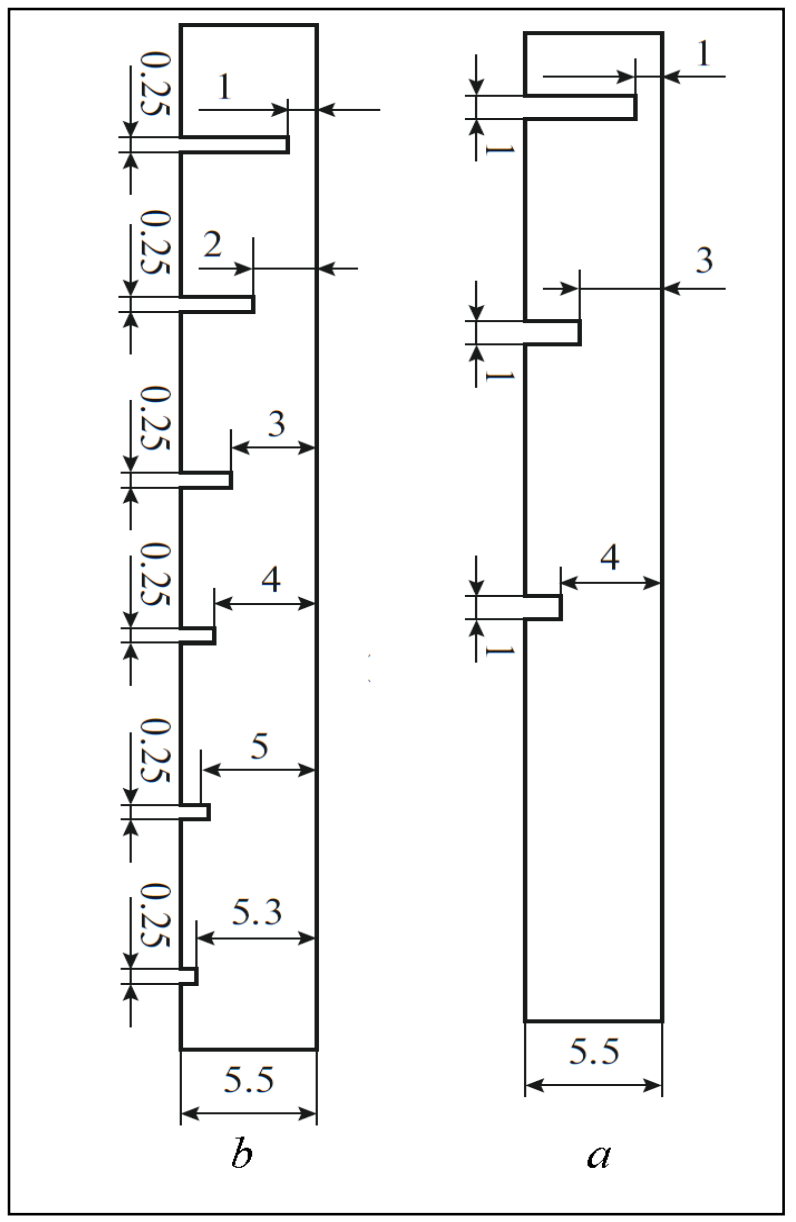

Fig. 3. The appearance of sample № 1(a) and №2(b), size - in mm

Scanning from the flaw-free side of the sample was carried out to determine the sensitivity of the transducer to flaws in the metal depth.

During the experiments with the first plate, the induced voltage on the exciting plate of the transducer was $2 \mathrm{~V}$.

The results from the first plate with flaws with a thickness of $1 \mathrm{~mm}$ allowed us to explicitly detect all three slots from the drop in the signal amplitude at $500 \mathrm{~Hz}$ and signal amplitude of $2 \mathrm{~V}$ (Fig. 4). This was approximately $0.75 \mathrm{~V}$ at the first flaw; $0.2 \mathrm{~V}$-- at the second flaw, and $0.1 \mathrm{~V}-$ at the third flaw.

The results of the second plate at $500 \mathrm{~Hz}$ and a signal amplitude of $3 \mathrm{~V}$ allowed us to detect five flaws (Fig. 5). The signal amplitude drop at the first flaw was $2.5 \mathrm{~V}$. At the second flaw, the signal amplitude drop was $1 \mathrm{~V}$; at the third flaw, it was $0.4 \mathrm{~V}$; at the fourth flaw, it was $0.2 \mathrm{~V}$; and at the fifth flaw - $0.1 \mathrm{~V}$. A change of the signal response during transmission over the sixth flaw was not detected due to its low value. The value of using a system of amplifiers and band-pass filters in search for deep-occurrence flaws is shown in Fig. 6. The flaws at depths of $3 \mathrm{~mm}$ and more are virtually unnoticeable against the background of the noise.

The experimental results show the efficiency of the designed measuring system for searching for flaws with a thickness from $0.25 \mathrm{~mm}$ that lie at depths of up to $5 \mathrm{~mm}$.

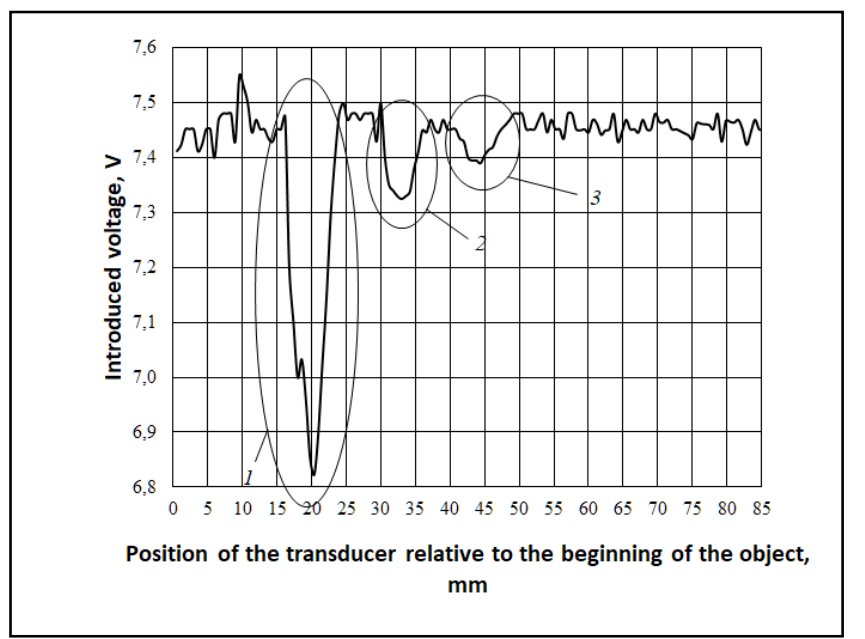

Fig. 4. Results of scanning plates 1 without filtering

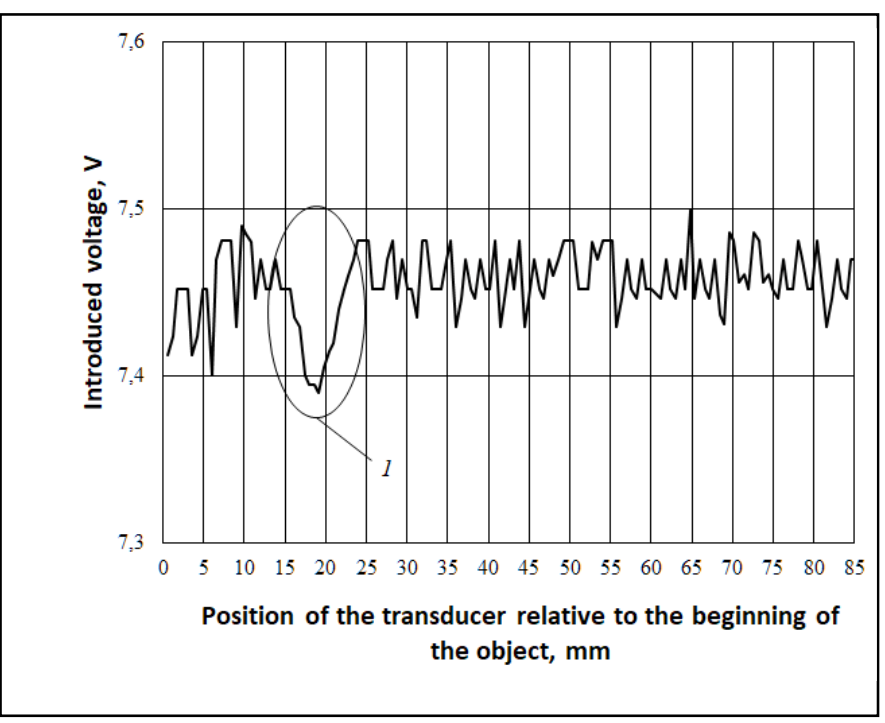

Fig. 5. Results of scanning plates 2 without filtering

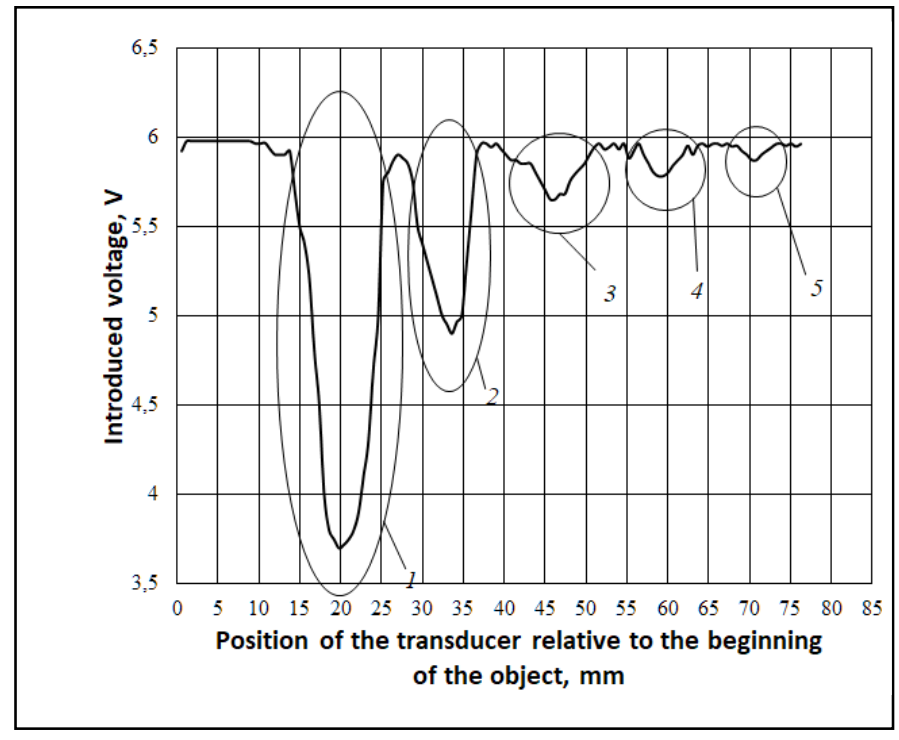

Fig. 6. Results of scanning plates 2 with filtering 


\section{B. Scanning the welded seams of titanium alloys}

The measured characteristic is the voltage induced by the eddy current field formed in the inspected object. Prior to the measurements, the sensor was calibrated by determining the supplied voltage from the area free from defects. In these experiments, the section for calibration was selected on a defect-free plate produced from titanium identical to the titanium used in the investigations. Calibration was carried out at different frequencies. The frequency was calibrated in the range of $500-2000 \mathrm{~Hz}$ in $100 \mathrm{~Hz}$ steps. Further scanning was carried out by moving the sensor along or across the welded joint or across the region with the defects. In the experiments, it was established that the optimum frequency range of the electromagnetic field of the exciting winding for investigating titanium is $1500-1700 \mathrm{~Hz}$.

A set of measurements was performed on VT1-0 technical titanium plates that were connected by welded seams to demonstrate the appropriateness of the proposed unit for the determination of the quality of welded seams. The plate thickness was $5 \mathrm{~mm}$ and the width of the welded seam was 5 mm (Fig.7).

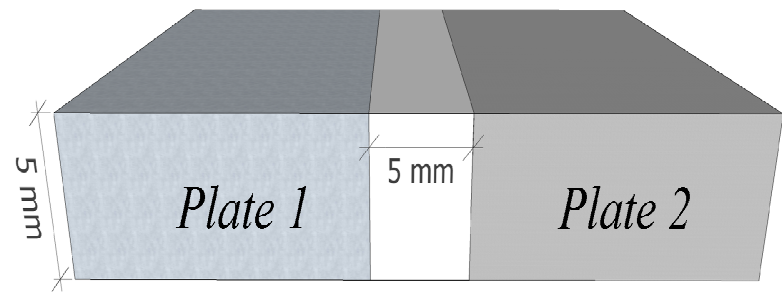

Fig. 7. The appearance of the titanium sample

Before the measurements were started, the transducer had been calibrated. Prior to the measurements, the sensor was calibrated by determining the supplied voltage from the area free from defects. In these experiments, the section for calibration was selected on a defect-free plate produced from titanium identical to the titanium used in the investigations.

Calibration was carried out at different frequencies. The frequency was calibrated in the range of $500-2000 \mathrm{~Hz}$ in 100 $\mathrm{Hz}$ steps. Further scanning was carried out by moving the sensor along or across the welded joint or across the region with the defects. In the experiments, it was established that the optimum frequency range of the electromagnetic field of the exciting winding for investigating titanium is $1500-1700 \mathrm{~Hz}$.

In order to determine the homogeneity of the welded joints, the specimens were scanned along the surface of the welded joint. No large changes were found in the signal amplitude. The results of the experiment are presented in Fig. 8.

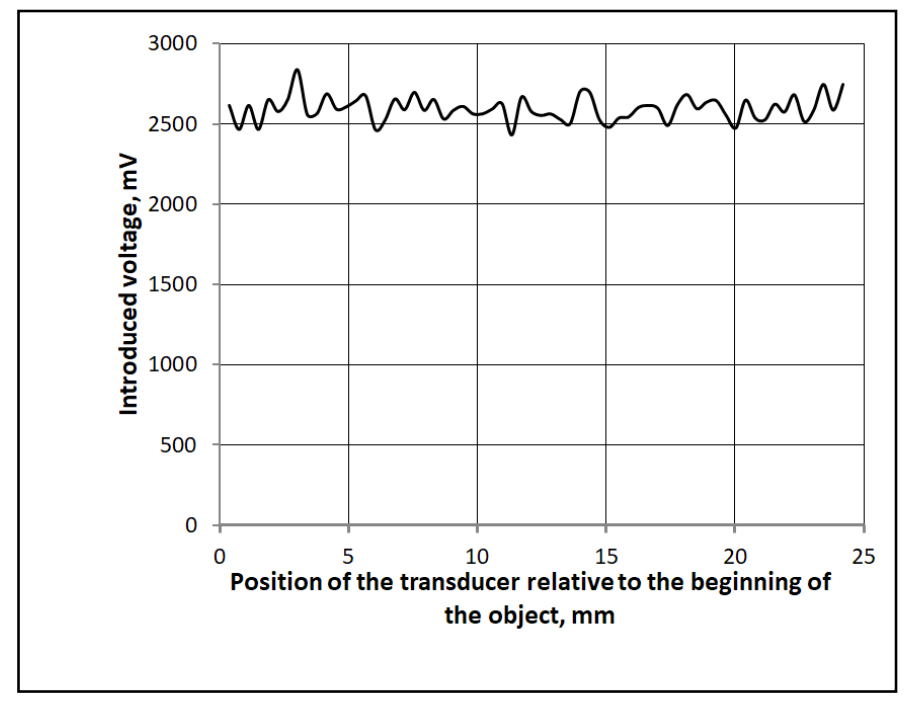

Fig. 8. The response value during scanning lengthwise of the welded seam

The experimental results indicate the relatively homogeneous structure of the welded joint, but do not provide any information on the quality of the welded joint. The results of these experiments can be used to make conclusions only about the uniformity of distribution of defects along the welded joint or about the absence of defects.

At the next stage of the experiments, scanning was carried out across the welded joint. The welded joints were $150 \mathrm{~mm}$ long. The welded joint was divided into 30 regions with $5 \mathrm{~mm}$ each in the 30 regions so as to record the signal from both the welded joint and directly from the sheets. The dependences were averaged-out. The results of the experiment are presented in Fig. 9, 10.

The scanning of specimen №1 found no deviation of the signal amplitude within the welded seam. In specimen №2, the influence of a deficient weld seam on the inserted voltage is clearly traced by a significant drop in the signal amplitude in the weld seam area in comparison with the slabs area.

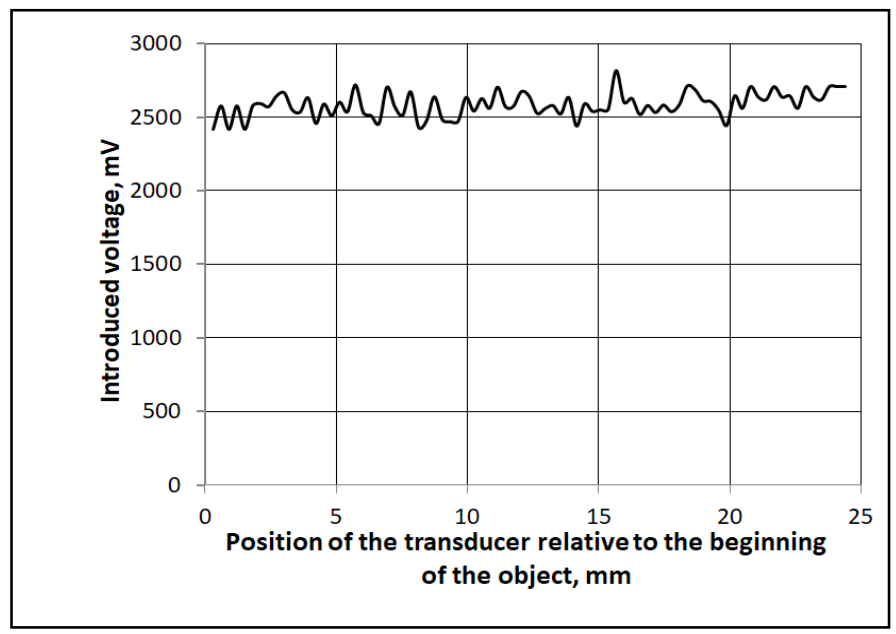

Fig. 9. The response value during scanning across welded seam specimen №1 


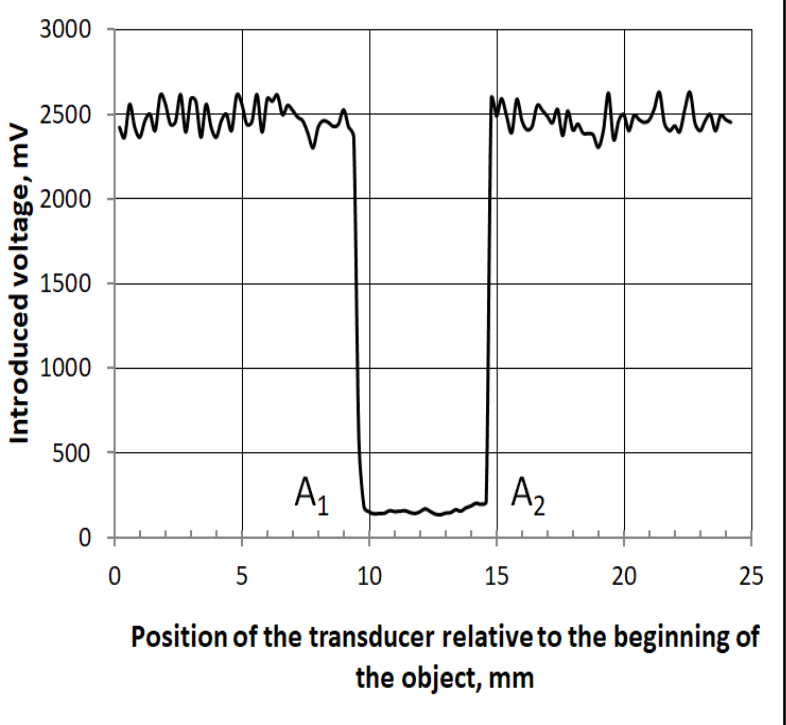

Fig. 10. The response value during scanning welded seam specimen № 2, $\mathrm{A}_{1}-$ $\mathrm{A}_{2}$ are the boundaries of the welded seam

The experimental results were used to conclude that the quality of the welded joint in specimen №2 is low. The low quality of welding was also confirmed directly by sectioning the welded joint. Scanning of specimen №1 showed that there are no deviations of the signal amplitude within the limits of the welded joint. Examination of the sections of the welded joint in specimen №1 showed the high quality of the welded joint.

Additional experiments were carried out in simulation of a similar amplitude drop. In these experiments, two titanium sheets of the same thickness were placed in tight contact and, subsequently, the interface was scanned with a scanning frequency of $1600 \mathrm{~Hz}$. The results of the experiment are presented in Fig. 11.

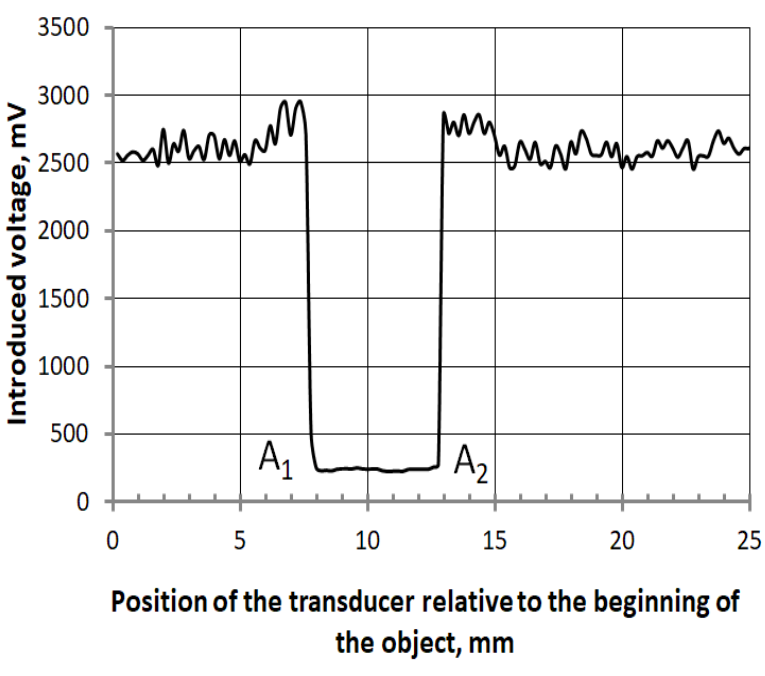

Fig. 11. The response value during scanning in the area of two slabs junction. $A_{1}-A_{2}$ correspond to the edges of the area where the junction presence influences the inserted voltage.
These experiments yielded dependence identical to that shown in Fig. 10 in the region of the welded joint in the specimen. The signal amplitude in the region of the interface decreased by more than an order of magnitude in comparison with the signal amplitude from the sheets.

\section{CONCLUSIONS}

The experimental results show great potential for the detection of defects hidden in the depth of metals by means of eddy-current measuring systems. Whereas eddy-current monitoring could be previously used only to find surface defects (cracks, grooves, and discontinuities in the surface layer), the use of superminiature eddy-current transformers and specialized software permits the localization of the magnetic field within a small section of the sample and penetration of the field to considerable depth, with the appropriate choice of frequency for the field created by the exciting winding. The results of the experiments conducted showed a high efficiency of the developed method in the search for defects of the titanium slabs weld seams and in the evaluation of the welding quality. Thanks to the change of the eddy-current transducer signal amplitude in the area of the weld seam, the authors succeeded in defining the edges of the weld seam exactly, its low quality being obvious due to a steep drop in the signal amplitude. Likewise, the dependence, received as a result of analysis of Specimen 2, characterized by a high welding quality, and scanning showed the absence of any significant signal amplitude changes.

So, the analysis of the eddy-current transducer response can be used for the evaluation of the performed welding quality and duralumin alloys.

\section{References}

[1] L. Barbato, N. Poulakis, A. Tamburrino, T. Theodoulidis, S. Ventre, "Solution and extension of a new benchmark problem for eddy current nondestructive testing", IEEE Trans. Magn, vol. 51(7), pp. 1-7, July 2015.

[2] R.J. Prance, T.D. Clark, H. Prance, "Compact room-temperature induction magnetometer with super-conducting quantum interference level field sensitivity", Rev. Sci. Instrum, vol. 74, pp. 3735-3739, August 2000.

[3] R.J. Prance, T.D. Clark, H. Prance, "Ultra-low noise induction magnetometer for variable temperature operation", Sens. Actuators, vol. 85, pp. 361-364, August 2003.

[4] A. Matsunawa, N. Seto, J. Kim, M. Mizutani, S. Katayama, "Dynamics of keyhole and molten pool in high power CO2 laser welding", Proceedings High-Power Lasers in Manufacturing, vol.3888, pp. 34-45, November 1999 [Advanced High-Power Lasers and Applications, p. 570, 2000].

[5] W. Deng, L.K. Shark, B.J. Matuszewski, J.P. Smith, G. Cavaccini, "CAD model-based inspection and visualisation for 3D non-destructive testing of complex aerostructures", Insight: Non-Destructive Testing and Condition Monitoring, vol. 46(3), pp. 157-161, March 2004.

[6] X.E. Gros, J. Bousique, K. Takahashi, "NDT data fusion at pixel level", NDT\&E Int, vol. 32(5), pp. 283-292, July1999.

[7] P. Vargas, C.F. Baxter, R.W. Schutz, "A level 3 BS7910 ECA for a titanium stress joint for use on a high motion floater in the Gulf of Mexico", Digests The 30th International Conference on Offshore Mechanics and Arctic Engineering, pp. 581-591, June 2011 [30th The International Conference on Ocean, Offshore and Arctic Engineering, p. 956, 2011]. 
[8] A.M. Horn, M. Hauge, P.A. Rostadsand, B. Bjornbakk, P. Dahlberg, and T. Fossesholm, "Cost effective fabrication of large diameter high strength titanium catenary riser", Digests The 21st International Conference on Offshore Mechanics and Arctic Engineering, pp. 331337, June 2002 [21th The International Conference on Ocean, Offshore and Arctic Engineering, p. 792, 2002].

[9] T. Chady, P. Frankowski, "Extremely short impulse eddy current system for titanium and Inconel samples testing", AIP Conference Proceedings, vol. 1335, pp. 1709-1713, July 2011 [Progress In Quantitative Nondestructive Evaluation, p. 1799, 2011].
[10] S. Dmitriev, A. Ishkov, V. Malikov, and A. Sagalakov, "Subminiature eddy current transducers for studying metal-dielectric junctions", Instr. and Exp. Tech, vol. 57(6), pp. 751-754, June 2014.

[11] S. Dmitriev, L. Shevtsova, A. Katasonov, V. Malikov, and A. Sagalakov, Subminiature eddy current transducers for studying semiconductor material", Journal of Physics: Conference Series, vol. 643, pp. 1-5, April 2015 [2nd International School and Conference Saint-Petersburg OPEN on Optoelectronics, Photonics, Engineering and Nanostructures, p. 1236, 2015]. 